\title{
Frequency of Hepatopulmonary Syndrome (HPS) Among Patients With Liver Cirrhosis: A Letter to Editor
}

\author{
Ali Mokhtarifar, ${ }^{1}$ Hamidreza Azimi, ${ }^{1}$ Abbas Esmaeelzadeh, ${ }^{1}$ Mahmood Ebrahimi, ${ }^{2}$ and Seyed \\ Ahmad Eghbali, \\ ${ }^{1}$ Department of Gastroenterology, Mashhad University of Medical Sciences, Mashhad, IR Iran \\ ${ }^{2}$ Department of Cardiology, Mashhad University of Medical Sciences, Mashhad, IR Iran \\ ${ }^{*}$ Corresponding Author: Seyed Ahmad Eghbali, Department of Gastroenterology, Mashhad University of Medical Sciences, Mashhad, IR Iran. Tel: +98-9133559980, \\ E-mail: drahmadeghbali@gmail.com
}

Received 2016 January 2; Accepted 2016 January 25

Keywords: Hepatopulmonary Syndrome (HPS), Cirrhosis, Liver Diseases

\section{Dear Editor,}

Hepatopulmonary syndrome (HPS) is a complication of liver disease. It is most frequently related to portal hypertension (with or without cirrhosis), although chronic liver disease of almost any etiology could be related to HPS $(1,2)$. Moreover, some acute liver diseases are related to HPS, such as ischemic hepatitis (3). HPS can be diagnosed when the following disorders have been approved $(1,4$, 5); liver disorder, impaired oxygenation, intrapulmonary vascular anomalies, referred to as intrapulmonary vascular dilatations (IPVDs) and lack of intrinsic cardiopulmonary problem. HPS patients finally develop dyspnea on exertion, at rest, or both, commonly after years of liver disease. Dyspnea may be accompanied by pulmonary findings that are more specific for HPS $(1,6)$ such as platypnea and orthodeoxia. The frequency of hepatopulmonary syndrome in patients with chronic liver disease is about 4 to $47 \%$ regarding the criteria of diagnosis and used methods (7-12). The current study evaluated the prevalence of this complication in patients with cirrhosis.

Thirty eight patients with cirrhosis were included in this study. Chest X-ray, air-contrast echocardiography, ABG in supine and standing positions, Tc99 MAA lung perfusion scan, PFT (pulmonary function test), serum bilirubin, PT and albumin were evaluated in patients. Hepatopulmonary syndrome was diagnosed in patients who had intrapulmonary vascular shunting and pulmonary gas exchange abnormalities.

Among 38 patients, 28 persons were male (\%73.7) and 10 females (\%26.3). The mean age was $46.2 \pm 13.6$ (ranged 18 64 years). The most common cause of cirrhosis was hepatitis B. Among 29 patients (\%76.3), hepatitis B and among 3 patients (\%7.6) hepatitis $\mathrm{C}$ was diagnosed. Six patients (\%15.8) had cryptogenic cirrhosis. Eleven patients (\%28.9) had significant hypoxemia ( $\mathrm{pa}_{2}<70$ ) and 24 patients (\%71.1) had not hypoxemia.

Using echocardiography, 9 patients (23.7\%) had pulmonary shunt. Also using radio isotope scan, 2 patients (\%5.3) had pulmonary shunt. No patients with positive results in scan had contrast echocardiography. Therefore, pulmonary shunt frequency was $\% 23.7$.

Six patients (15.8\%) had HPS. Three patients (9.9\%) had pulmonary shunt without hypoxemia or elevated $\mathrm{p}(\mathrm{A}-\mathrm{a})$ $\mathrm{O}_{2}$ that are introduced subclinical HPS or IPVDs.

Fourteen patients (\%36.8) had child score A, 19 patients (\%50) child score B and 5 (\%13.2) child score C.

The findings of the present study showed the prevalence of HPS and intrapulmonary vascular dilatation syndrome in patients with cirrhosis. Air-contrast echocardiography was more effective in diagnosis of intrapulmonary vascular shunting compared to Tc99 MAA lung perfusion scan. No significant relation was found between sex, age, duration, severity, and primary reason of cirrhosis with hepatopulmonary syndrome, but intrapulmonary vascular shunting was more usual in women patients. Spider angioma, orthodeoxia, low serum albumin, and ascites were determined to be suitable clinical indicators for hepatopulmonary syndrome.

\section{References}

1. Rodriguez-Roisin R, Krowka MJ. Hepatopulmonary syndrome--a liver-induced lung vascular disorder. $N$ Engl J Med. 2008;358(22):2378-87. doi: 10.1056/NEJMra0707185. [PubMed: 18509123]

2. Kaymakoglu S, Kahraman T, Kudat H, Demir K, Cakaloglu Y Adalet I, et al. Hepatopulmonary syndrome in noncirrhotic portal hypertensive patients. Dig Dis Sci. 2003;48(3):556-60. [PubMed:12757170] 
3. Fuhrmann V, Madl C, Mueller C, Holzinger U, Kitzberger R, Funk GC, et al. Hepatopulmonary syndrome in patients with hypoxic hepatitis. Gastroenterology. 2006;131(1):69-75. doi: 10.1053/j.gastro.2006.04.014. [PubMed:16831591]

4. Rodriguez-Roisin R, Krowka MJ, Herve P, Fallon MB, E. R. S. Task Force Pulmonary-Hepatic Vascular Disorders Scientific Committee. Pulmonary-Hepatic vascular Disorders (PHD). Eur Respir J. 2004;24(5):861-80. doi: 10.1183/09031936.04.00010904. [PubMed: 15516683]

5. Fritz JS, Fallon MB, Kawut SM. Pulmonary vascular complications of liver disease. Am J Respir Crit Care Med. 2013;187(2):133-43. doi: 10.1164/rccm.201209-1583CI. [PubMed: 23155142]

6. Krowka MJ, Cortese DA. Hepatopulmonary syndrome: An evolving perspective in the era of liver transplantation. Hepatology. 1990;11(1):138-42. doi:10.1002/hep.1840110123. [PubMed:2403962]

7. Krowka MJ. Hepatopulmonary syndrome. Current concepts in diagnostic and therapeutic considerations. CHEST Journal. 1994;105(5):1528. doi:10.1378/chest.105.5.1528.

8. Schenk P, Schöniger-Hekele M, Fuhrmann V, Madl C, Silberhumer G, Müller C. Prognostic significance of the hepatopul- monary syndrome in patients with cirrhosis. Gastroenterology. 2003;125(4):1042-52. doi: 10.1016/s0016-5085(03)01207-1. [PubMed: 14517788

9. Krowka MJ, Tajik AJ, Dickson ER, Wiesner RH, Cortese DA. Intrapulmonary vascular dilatations (IPVD) in liver transplant candidates. Screening by two-dimensional contrast-enhanced echocardiography. Chest. 1990;97(5):1165-70. [PubMed: 2331913]

10. Stoller JK, Lange PA, Westveer MK, Carey WD, Vogt D, Henderson JM. Prevalence and reversibility of the hepatopulmonary syndrome after liver transplantation. The Cleveland Clinic experience. West J Med.1995;163(2):133-8. [PubMed:7571560]

11. Hopkins WE, Waggoner AD, Barzilai B. Frequency and significance of intrapulmonary right-to-left shunting in end-stage hepatic disease. Am J Cardiol. 1992;70(4):516-9. doi: 10.1016/00029149(92)91200-n. [PubMed:1642191]

12. Arguedas MR, Singh H, Faulk DK, Fallon MB. Utility of pulse oximetry screening for hepatopulmonary syndrome. Clin Gastroenterol Hepatol. 2007;5(6):749-54. doi: 10.1016/j.cgh.2006.12.003. [PubMed:17392034] 